Clarke, P. H. \& Meadow, P. M. (1959). J. gen. Microbiol. 20, 144-155

\title{
Evidence for the Occurrence of Permeases for Tricarboxylic Acid Cycle Intermediates in Pseudomonas aeruginosa
}

\author{
By PATRICIA H. ClaRKE and PAULINE M. MEADOW \\ Department of Biochemistry, University College London
}

\begin{abstract}
SUMMARY : Washed suspensions and cell-free extracts of Pseudomonas aeruginosa grown on Lemco agar, to which intermediates of the tricarboxylic acid cycle had been added, were tested for their ability to oxidize succinate, fumarate, malate, pyruvate, acetate, $\alpha$-oxoglutarate and citrate. Whole organisms had lag periods of $2-3 \mathbf{h r}$. before citrate was oxidized rapidly, except when citrate or acetate had been added to the growth medium. There were lag periods of about $10 \mathrm{~min}$. before rapid and linear oxidation of succinate by organisms grown on acetate; of fumarate by organisms grown on acetate or pyruvate; and of acetate by organisms grown on malate, pyruvate, $\alpha$-oxoglutarate, fumarate or succinate. There were no lags for malate, pyruvate or $\alpha$-oxoglutarate by organisms grown on any of the substrates tested. Organisms grown on malonate or Lemco agar to which no additions had been made had lags for all the substrates. Glucose-grown organisms had lags for all the intermediates except succinate. Only malonate-grown organisms oxidized malonate rapidly and linearly, and organisms grown without malonate had lag periods of 2-3 hr. before oxidizing this substrate.

Cell-free extracts from organisms with lag periods before the oxidation of citrate, acetate, fumarate, malate, succinate and $\alpha$-oxoglutarate were shown to oxidize these substrates without a lag period. Pyruvate and malonate were not oxidized by any of the extracts including those from organisms grown on these substrates. Chloramphenicol inhibited the adaptation to substrates by whole organisms but was without effect on the oxidation by cell-free extracts. The significance of these findings in relation to the hypothesis of specific permeases for the transport of organic molecules into the cell is discussed.
\end{abstract}

Studies on the kinetics of induction of Escherichia coli $\beta$-galactosidase (Rickenberg, Cohen, Buttin \& Monod, 1956) led to the hypothesis that the presence of an inducer, besides producing the specific enzyme $\beta$-galactosidase, also resulted in the production of a specific protein ( $\beta$-galactoside-permease) which enabled the organisms to accumulate $\beta$-galactosides. In a review Cohen $\&$ Monod (1957) suggested that most, if not all, organic molecules may enter the cell by the action of similar highly stereospecific permeases. We were thus led to consider that the observed oxidation of some of the intermediates of the tricarboxylic acid cycle by extracts, but not by whole bacteria, might be due to the absence of the necessary permeases.

Kogut \& Podoski (1953) and Barrett \& Kallio (1953) showed that cell-free extracts of Pseudomonas spp. oxidized certain intermediates of the tricarboxylic acid cycle rapidly and linearly, whereas with whole organisms there was a lag period before a linear oxidation rate was reached. Both groups of workers suggested that the lag period for whole organisms might involve 


\section{Permeases in Pseudomonas aeruginosa}

making the substrate accessible to the enzyme, either across the cell membrane or to some special site within the cell. We thought that the lag periods might be due to the synthesis of the specific permeases required to transport the substrates into the cell. The experiments with Pseudomonas aeruginosa described in this paper were designed to test this hypothesis by comparing the oxidative capacities of cell-free extracts and whole organisms grown with different substrates, and the effect of possible inhibitors of the adaptive process. Some of these results were presented in a preliminary report (Meadow \& Clarke, 1958).

\section{METHODS}

Cultivation of bacteria. Pseudomonas aeruginosa was obtained from the National Collection of Type Cultures as NCTC 8203. Stock cultures were maintained on slopes of Lemco agar $(10 \mathrm{~g}$. peptone; $10 \mathrm{~g}$. Lab. Lemco; $5 \mathrm{~g} . \mathrm{NaCl} ; 10 \mathrm{~g}$. agar; water to $1 \mathrm{l}$; $\mathrm{pH} 7 \cdot 4)$. The inoculum was grown for $6 \mathrm{hr}$. at $37^{\circ}$ with shaking, in tubes of Lemco broth (composition as above without agar). For experiments in the Warburg apparatus, organisms were grown in Roux bottles for $18 \mathrm{hr}$. at $37^{\circ}$ on the surface of $100 \mathrm{ml}$. Lemco agar to which various intermediates of the tricarboxylic acid cycle or glucose or malonate, had been added to give a final concentration of $0 \cdot 4 \%(\mathrm{w} / \mathrm{v})$. One tube of a $6 \mathrm{hr}$. subculture in Lemco broth was used to inoculate each Roux bottle. After growth the organisms were washed off the agar with distilled water, filtered through gauze to remove particles of agar, harvested by centrifugation and washed with $50 \mathrm{ml}$. distilled water. The organisms from two Roux bottles were then resuspended in $20 \mathrm{ml}$. of $0.05 \mathrm{M}$-phosphate buffer $(\mathrm{pH} 7 \cdot 4)$ and diluted approximately tenfold for the manometric experiments. In different experiments the amount of organisms used varied from equiv. 5 to $20 \mathrm{mg}$. dry wt./ml.

Preparation of cell-free extracts. These were prepared by forcing the undiluted suspensions (equiv. c. $200 \mathrm{mg}$. dry wt./ml.) through a small aperture at $10,000 \mathrm{lb}$./sq.in. in a bacterial press modified from that described by Milner, Lawrence \& French (1950). Cellular debris was removed by centrifugation at $20,000 \mathrm{~g}$ for $5 \mathrm{~min}$. and the supernatant fluid used for the Warburg estimations.

Manometric methods. Oxygen uptake was measured by the conventional Warburg technique at $37^{\circ}$ with air as the gas phase and $0.2 \mathrm{ml} .40 \%(\mathrm{w} / \mathrm{v})$ potassium hydroxide in the centre cup. The main compartment of the Warburg vessel contained $1 \mathrm{ml}$. cell-free extract or diluted suspension of organisms, $0 \cdot 2 \mathrm{ml}$. of inhibitor when used and enough $0.05 \mathrm{M}$-phosphate buffer to give a total volume of $3.0 \mathrm{ml}$; the substrate $(0.4 \mathrm{ml}$. of a $4 \%, \mathrm{w} / \mathrm{v}$, solution) was added from the side arm after equilibration. For experiments on malonate decarboxylase, the potassium hydroxide was omitted from the centre well and the experiments were carried out in $0.05 \mathrm{M}$-phosphate buffer $(\mathrm{pH} 6 \cdot 1)$ in an atmosphere of nitrogen.

Reagents. Chemicals were all of 'Analar' grade when available. The buffer used throughout was Sørenson's phosphate buffer (0.05-M, pH 7·4 and 6.1). 
The tricarboxylic acid cycle intermediates, glucose and malonate were obtained from British Drug Houses Ltd., the 8-azaguanine and nitroarginine from L. Light and Co., penicillin (Na salt) from Glaxo Ltd. and chloramphenicol from Parke Davis Ltd.

\section{RESULTS}

\section{Comparison of whole organisms and cell-free extracts}

The organisms were grown on Lemco agar to which various intermediates had been added at $0.4 \%(\mathrm{w} / \mathrm{v})$. The rates of oxidation of these compounds by washed suspensions, and the occurrence of lag periods before the maximum rate of oxidation was reached, depended on which compound had been added to the medium. Kogut \& Podoski (1953), using a fluorescent pseudomonad isolated from soil, Barrett \& Kallio (1953), using Pseudomonas fluorescens, and Stone \& Wilson (1952), using Azotobacter vinelandii, had shown that although whole organisms had lag periods before oxidizing some of the tricarboxylic acid cycle intermediates there was no lag period with cell-free extracts. With Pseudomonas aeruginosa we found similar though not identical results.

A typical series of results, in this case with malate-grown organisms, is shown in Fig. $1(a-d)$. The washed suspensions oxidized malate, succinate, pyruvate and $\alpha$-oxoglutarate at a linear rate from the time of adding the substrate (Fig. 1 a). Acetate was oxidized linearly only after a lag period of about 10 min. (Fig. $1 b$ ) and citrate was only oxidized rapidly after a lag period of about $3 \mathrm{hr}$. (Fig. 1c). Cell-free extracts, prepared with the bacterial press, oxidized citrate, succinate, fumarate, malate, acetate and $\alpha$-oxoglutarate rapidly with no initial lag period (Fig. $1 d$ ). The rate of citrate oxidation of these extracts was greater even than the rate of oxidation of malate, the substrate on which the organisms had been grown. These results are in agreement with the view that the lag period represents an adaptation which is concerned with the permeability of the organism to the substrate rather than the adaptive production of the oxidative enzymes.

\section{The effect of chloramphenicol}

The lag period was difficult to detect when it was of very short duration and the initial rate of oxidation in the first $5 \mathrm{~min}$. was above the endogenous respiration. Kogut \& Podoski (1953) showed that the adaptation to maximum rate of oxidation could be prevented by inhibiting protein synthesis by ultraviolet irradiation. Barrett \& Kallio (1953) were able to inhibit this adaptation with amino acid analogues. It was thought that chloramphenicol should also prevent the adaptation, and should make it easier to detect lag periods of 5-15 min. Accordingly, the rates of oxidation of the substrates were measured in the presence and absence of chloramphenicol. When there was a lag before a linear rate of oxidation was established, a clear difference was seen between the rates of oxidation with and without chloramphenicol (60 $\mu \mathrm{g} . / \mathrm{ml}$.). When no lag was detected for a particular substrate then its rate of oxidation 

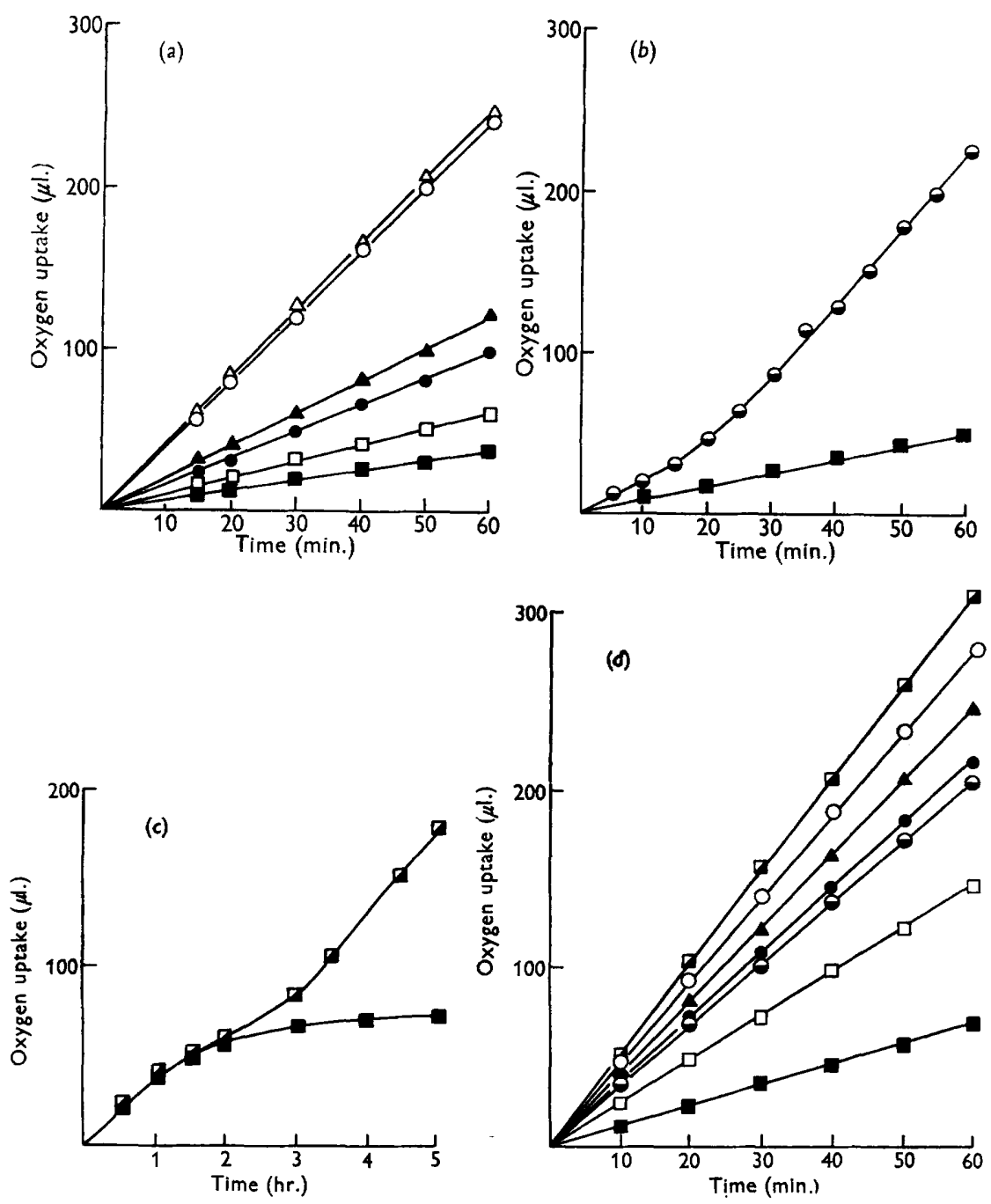

Fig. $1 a-d$. Oxidative activity of malate-grown Pseudomonas aeruginosa. (a) Whole organisms, $\triangle-\triangle$, pyruvate; $O-O$, succinate; $\Delta-\Delta$, malate; $-\longrightarrow$, fumarate; $\square-\square$, $\boldsymbol{\alpha}$-oxoglutarate; $\square-\square$, endogenous. (b) Whole organisms, $\ominus-\ominus$, acetate; $\square-\mathbf{\square}$, citrate and endogenous. $(c)$ Whole organisms, $\square-\square$, citrate: $\square-\square$, endogenous. (d) Cell-free extracts, $\square-\square$, citrate; $O-O$, succinate; $\Delta-\Delta$, malate; fumarate; $\ominus-\vartheta$, acetate; $\square-\square, \alpha$-oxoglutarate; $\square-\square$, endogenous. (50 $\mu$ mole substrates.)

was unchanged by the addition of chloramphenicol. Figures $2 a, b$ show typical results with organisms grown on pyruvate. Pyruvate, succinate, malate and $\alpha$-oxoglutarate were oxidized linearly from the moment of tipping and the rate was not altered by the addition of chloramphenicol (Fig. 2a). Fumarate and acetate gave short lag periods of about $10 \mathrm{~min}$. and there was a marked difference in the rates of oxidation of these substrates in the presence and absence of chloramphenicol (Fig. 2b). 
Batches of organisms were grown with each of the substrates in turn, and tested in this way for lag periods and for differences in the rate of oxygen uptake with and without chloramphenicol. Whenever a lag period (however short) was observed, there was a clear-cut difference to be seen by adding chloramphenicol. The rate of oxidation by cell-free extracts was unchanged by the addition of the same concentration of chloramphenicol.
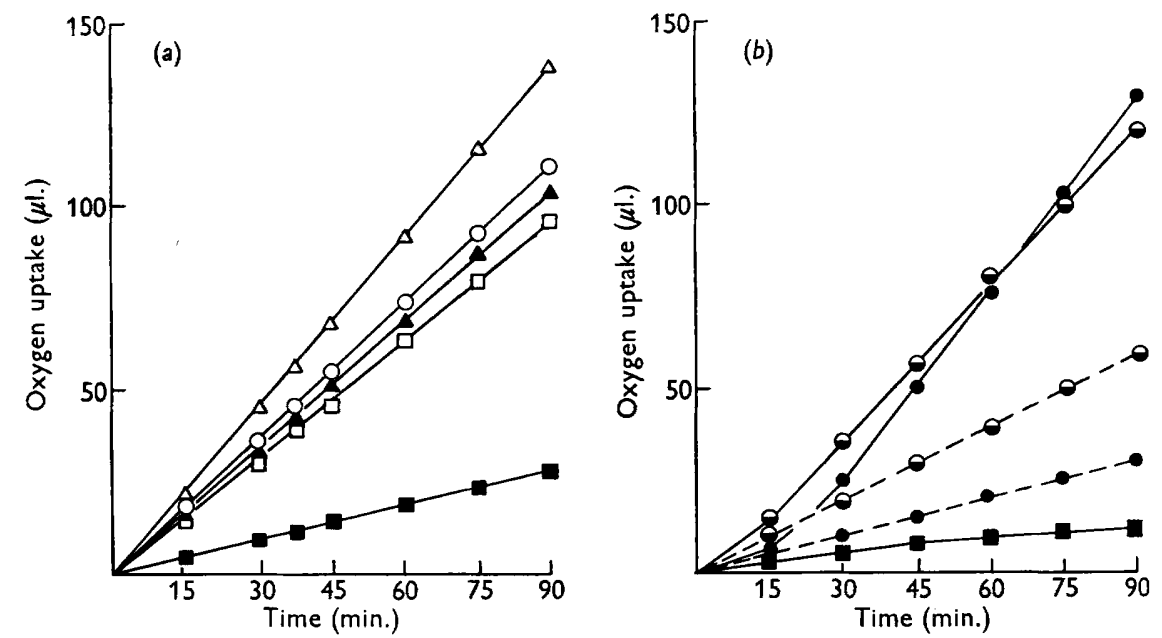

Fig. 2a,b. Effect of chloramphenicol on the oxidative activity of pyruvate-grown Pseudomonas aeruginosa. (a) Substrates with rates unchanged in the presence of chloramphenicol, $\triangle-\Delta$, pyruvate; $\bigcirc-O$, succinate; $\Delta-\mathbf{\Delta}$, malate; $\square-\square, \alpha$-oxoglutarate; $\square-\square$, endogenous. The lines represent rates in the presence and absence of $60 \mu \mathrm{g}$. chloramphenicol $/ \mathrm{ml}$. (b) Substrates with adaptation inhibited by chloramphenicol, _- no chloramphenicol; _- _-, with $60 \mu \mathrm{g}$. chloramphenicol $/ \mathrm{ml}$;

fumarate; $\ominus-\ominus$, acetate; $\square$, endogenous. (50 $\mu$ mole substrates.)

\section{Oxidation of citrate}

The oxidation of citrate represented a special case. Unless citrate or acetate had been added to the growth medium, there was a period of $2-3 \mathrm{hr}$. before citrate was oxidized at an appreciable rate. None of the other substrates had such long lag periods; but Stone \& Wilson (1952) observed lag periods of about an hour in the oxidation of malate and succinate by Azotobacter vinelandii grown on sucrose. It was thought that the short periods of adaptation occurred when the appropriate permease is deficient but not absent. Substrate will then enter the cell fast enough for a full complement of permease to be established quickly. In the case of citrate, the lag period was prolonged to $2-3 \mathbf{~ h r}$. and the oxidation rate was hardly above the endogenous during this time. This suggests that the organism was almost completely devoid of citrate-permease; citrate then entered only very slowly and it took a long time for the necessary energy to be made available for protein synthesis. We thought that if this were so, it should be possible to decrease the period of adaptation before the oxidation of citrate by providing at the same time a small amount of a substrate which was known to enter the cell and to be oxidized rapidly. Figure 3 
shows the effect of the addition of $1 \mu$ mole fumarate together with $50 \mu$ mole citrate on the citrate lag period. It can be seen that the lag period was shorter when $1 \mu$ mole fumarate was present, and that rapid linear oxidation occurred after $90 \mathrm{~min}$. instead of $180 \mathrm{~min}$. Chloramphenicol inhibited the adaptation to citrate both in the presence and absence of fumarate. Fumarate therefore can be regarded as providing energy for permease synthesis, rather than acting as a 'sparker' of the tricarboxylic acid cycle.

\section{Growth medium and oxidation rate}

Table 1 summarizes the results obtained for the oxidation of various substrates by organisms which had been grown on media to which one of these substrates had been added. The washed suspensions were all tested with and without chloramphenicol to confirm short lag periods. The $Q_{\mathrm{O}_{2}}$ values are given for a single batch of organisms on each substrate, but at least two batches of organisms were grown on each substrate, and although the batches varied in activity, the relative rates of oxidation of the various substrates by organisms grown on the same medium appeared to be the same and the same lag periods were found.

Table 1. The oxidation of tricarboxylic acid cycle intermediates by washed suspensions of Pseudomonas aeruginosa grown with these substrates in the medium

\begin{tabular}{|c|c|c|c|c|c|c|c|c|}
\hline \multirow{2}{*}{$\begin{array}{l}\text { Substrate in } \\
\text { growth medium } \\
(0.4 \%, \mathrm{w} / \mathrm{v})\end{array}$} & \multicolumn{8}{|c|}{$Q_{\mathrm{O}_{2}}$} \\
\hline & Citrate & Acetate & Malate & Pyruvat & $\begin{array}{l}\alpha \text {-oxo- } \\
\text { glutarate }\end{array}$ & $\begin{array}{c}\text { Fuma- } \\
\text { rate }\end{array}$ & $\begin{array}{l}\text { Suc- } \\
\text { cinate }\end{array}$ & $\begin{array}{l}\text { No } \\
\text { sub. }\end{array}$ \\
\hline Citrate & 27 & 24 & 35 & 32 & 7 & 32 & 29 & $3 \cdot 3$ \\
\hline Acetate & 14 & 20 & 32 & 29 & 10 & {$[4.5]$} & {$[45]$} & 4 \\
\hline Malate & (14) & [23] & 17 & 22 & 10 & 16 & 22 & 4 \\
\hline Pyruvate & (24) & $\{29\}$ & 28 & 38 & 16 & [62] & 36 & 9 \\
\hline$\alpha$-oxoglutarate & (21) & {$[53]$} & 42 & 29 & 43 & 56 & 57 & $6 \cdot 8$ \\
\hline Fumarate & (24) & {$[20]$} & 21 & 64 & 31 & 44 & 28 & 17 \\
\hline Succinate & (19) & [21] & 42 & 40 & 12 & 51 & 43 & $5 \cdot 6$ \\
\hline
\end{tabular}

Brackets indicate lag periods before this rate was reached. ( ), 2-3 hr. lag; [ ], $10 \mathrm{~min}$. lag; \{\}$, 5$ min. lag.

The cell-free extracts prepared with the bacterial press were much more active than those prepared by shaking with glass beads in the Mickle apparatus. There was always a loss of activity as compared with whole organisms and, as might be expected, a variation in the oxidative activity of different extracts. Particular attention was paid to the activity of extracts from organisms which had shown lags towards certain substrates, and all those tested oxidized the substrate linearly irrespective of any lags found with whole organisms. None of the extracts prepared oxidized pyruvate, not even those from organisms grown on pyruvate; occasional preparations had lost the ability to oxidize acetate; and, as will be discussed later, none of the extracts oxidized malonate. No attempt was made to stimulate the oxidation of these substrates by the addition of supplementary co-factors. 


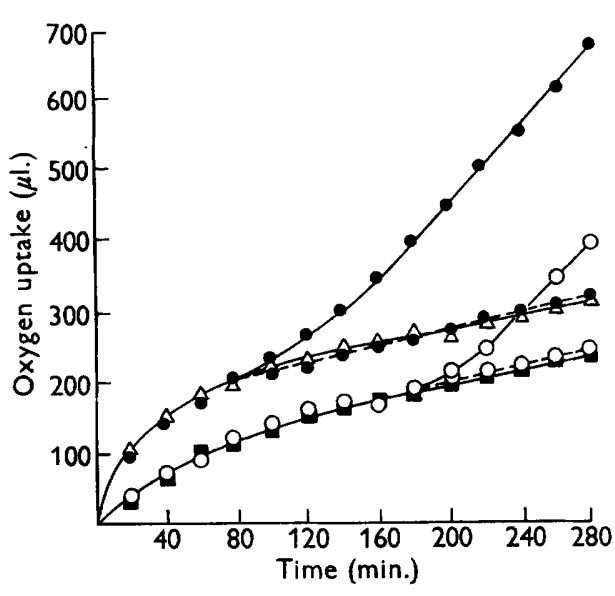

Fig. 3

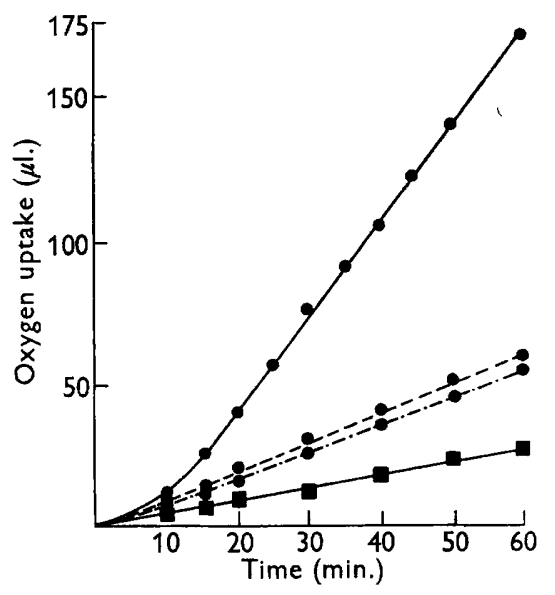

Fig. 4

Fig. 3. The effect of fumarate on the adaptation of fumarate-grown organisms to citrate oxidation. $-50 \mu$ mole citrate $+1 \mu$ mole fumarate; $--0,50 \mu$ mole citrate + $1 \mu$ mole fumarate $+60 \mu \mathrm{g}$. chloramphenicol $/ \mathrm{ml}$.; $\bigcirc-\mathrm{O}, 50 \mu$ mole citrate; $0---\mathrm{O}$, $50 \mu$ mole citrate $+60 \mu \mathrm{g}$. chloramphenicol $/ \mathrm{ml}$; $\triangle-\triangle, 1 \mu$ mole fumarate ; $\square$, endogenous.

Fig. 4. The effect of 8-azaguanine on the adaptation of pyruvate-grown organisms to fumarate oxidation. -0 , fumarate; - - -0 , fumarate $+60 \mu \mathrm{g}$. chloramphenicol/ ml.; --.--o, fumarate $+200 \mu \mathrm{g}$. 8-azaguanine/ml.; $\square-\square$, endogenous. (50 $\mu \mathrm{mole}$ fumarate used.)

\section{Effect of growth on other media}

Organisms were also grown on Lemco agar with no additions, and on Lemco agar to which $0.4 \%(\mathrm{w} / \mathrm{v})$ glucose or sodium malonate had been added. The results are given in Table 2 . It can be seen that organisms grown on Lemco

Table 2. Adaptation to the oxidation of tricarboxylic acid cycle intermediates by washed suspensions of Pseudomonas aeruginosa grown on glucose and malonate

\begin{tabular}{|c|c|c|c|c|c|c|c|c|}
\hline \multirow[b]{2}{*}{$\begin{array}{l}\text { Cells grown on } \\
\text { Lemco agar with } \\
0 \cdot 4 \%(w / v) \\
\text { substrate }\end{array}$} & \multicolumn{8}{|c|}{ Oxidation of substrates } \\
\hline & Citrate & $\begin{array}{l}\text { Ace- } \\
\text { tate }\end{array}$ & Malate & $\begin{array}{c}\alpha \text {-oxo- } \\
\text { gluta- } \\
\text { rate }\end{array}$ & $\begin{array}{c}\text { Fuma- } \\
\text { rate }\end{array}$ & $\begin{array}{l}\text { Suc- } \\
\text { cinate }\end{array}$ & Glucose & $\begin{array}{c}\text { Malo- } \\
\text { nate }\end{array}$ \\
\hline $\mathbf{0}$ & $\mathbf{L}^{*}$ & $\mathbf{L}^{\circ}$ & $\mathbf{L}^{*}$ & $\mathbf{L}^{*}$ & $\mathbf{L}^{*}$ & $\mathbf{L}^{*}$ & NT & $\mathbf{L}^{\mathbf{o}}$ \\
\hline Glucose & $\mathbf{L}^{*}$ & $\overline{\mathbf{L}}$ & $\overline{\mathbf{L}}$ & $\overline{\mathbf{L}}$ & $\overline{\mathbf{L}}$ & + & $t^{*}$ & $\mathbf{L}^{0}$ \\
\hline Malonate & $\mathbf{L}$ & $\mathbf{L}$ & $\mathbf{L}$ & $\mathbf{L}$ & $\mathbf{L}$ & $\mathrm{L}$ & NT & +0 \\
\hline
\end{tabular}

$+=$ no lag $=$ permease present; $L=$ lag; NT = not tested; $*^{*}=$ extracts tested and active; 0 extracts tested and inactive.

agar had lags for all the substrates tested. Extracts from these organisms oxidized all the substrates tested except malonate and acetate. Organisms grown on glucose had lags for all the substrates except glucose and succinate, while organisms grown on malonate had lags for all substrates except malonate. None of the extracts tested, including those from malonate-grown organisms, 
oxidized malonate. Gray (1952) found that washed suspensions of Pseudomonas aeruginosa could only oxidize malonate without a lag when they had been grown on malonate. He also showed that malonate-grown organisms could decarboxylate malonate, and that organisms and cell-free extracts, which had lost their ability to oxidize malonate, still had an active malonate decarboxylase. Dried organisms and cell-free extracts prepared from control organisms, grown without malonate, had no malonate decarboxylase activity. Gray (1952) and Wolfe, Ivler \& Rittenberg (1955), working with Pseudomonas fluorescens, suggested that the oxidation of malonate was preceded by decarboxylation. Hayaishi (1954) and Wolfe, Ivler \& Rittenberg (1954, 1955) showed that coenzyme $\mathbf{A}$ was involved and proposed that acetyl coenzyme $\mathbf{A}$ was formed.

In an experiment carried out in a nitrogen gas phase so that there could be no oxidation of the substrate, we found that whole organisms and cell-free extracts of Pseudomonas aeruginosa grown on malonate were able to decarboxylate malonate. The decarboxylase activity was very low and the $\mathrm{CO}_{2}$ output was less than a twentieth of the oxygen uptake of the same batch of organisms with malonate in air. Fumarate-grown organisms and cell-free extracts prepared from them did not decarboxylate malonate.

\section{Effect of other inhibitors}

Penicillin at 600 units $/ \mathrm{ml}$. had no effect on the initial rate of oxidation of acetate by acetate-grown organisms and did not inhibit the short adaptation (10 min.) to fumarate or the long adaptation (2-3 hr.) to citrate. At this high concentration the rate of acetate and fumarate oxidation decreased after 60 min., but this was thought to be a non-specific effect.

Nitroarginine was added to the organisms in a few experiments, but had no effect either on the oxidation rate or the adaptation. 8-Azaguanine inhibits the formation of some adaptive enzymes (Creaser, 1956). When it was added to pyruvate-grown organisms at $300 \mu \mathrm{g} . / \mathrm{ml}$. it had the same effect as chloramphenicol in inhibiting the adaptation to fumarate and citrate (Fig. 4). It was thought that this was probably due to inhibition of protein synthesis by interference with nucleic acid synthesis. However, when 8-azaguanine was tested with other substrates, the results were more complex. The oxidation of glucose by glucose-grown organisms was initially inhibited by the addition of 8-azaguanine; the oxidation of succinate by glucose-grown organisms, which oxidized succinate linearly, was not affected for the first 30-40 min., but after that there was a marked increase in the rate of oxidation above that for succinate alone. This increase in the rate of oxygen uptake with succinate and 8-azaguanine only occurred when excess $(50 \mu$ mole $)$ succinate was present. At low succinate concentrations (1-3 $\mu$ mole) the rate fell to that of the endogenous after all the succinate had been oxidized. Organisms tested with 8-azaguanine alone had no oxygen uptake over the endogenous even after $3 \mathrm{hr}$. Oxidation of guanine by glucose-grown organisms occurred after an initial lag period. The fate of 8 -azaguanine in these systems is being investigated further. 


\section{DISCUSSION}

The experiments gave results described in agreement with the earlier findings of Kogut \& Podoski (1953) and Barrett \& Kallio (1953) with other pseudomonads, that the adaptive phase observed in the oxidation of some of the intermediates of the tricarboxylic acid cycle is due to factors concerned with cellular permeability. We agree with Cohen \& Monod (1957) in considering that this adaptive phase is due to the production of specific permeases, the function of which is to enable these compounds to be transported into the cell. We interpret our results as follows. If the washed suspensions can oxidize a compound at a linear rate from zero time, then the cell already possesses an adequate amount of the specific permease for that compound; if there is a lag period of 5-15 min. before the linear rate of oxidation starts, then the cell already contains a little permease, but the amount is so low as to make the rate of entry of substrate into the cell the rate-limiting step in its oxidation; if the initial rate of oxidation remains little more than the endogenous although the extracts contain the relevant oxidative enzyme, then the necessary permease is considered to be absent. We are therefore interpreting the lag periods in these experiments as the period during which the necessary permeases are synthesized. We found that permease synthesis is inhibited by chloramphenicol and probably also by 8-azaguanine, although, as we have shown, care must be taken in the interpretation of the 8-azaguanine experiments since it has more than one effect in the systems we have described. Penicillin, on the other hand, appears to have no effect on permease synthesis in these systems. The evidence therefore depends on the presence or absence of lag periods and demonstration that protein synthesis is involved. The effect of fumarate in shortening the lag periods with citrate provides reasonable evidence that energy is required for permease synthesis. More rigorous proof for the existence of these permeases would be provided if it could be shown that the compounds are accumulated by the cell in the way in which Cohen \& Rickenberg (1955) have shown for the accumulation of $\beta$-galactosides by Escherichia coli. It is difficult to demonstrate the accumulation of a compound which is an essential metabolite and is rapidly oxidized, and for which suitable analogues are not readily available, but it is hoped to investigate this aspect at a later date.

Cohen \& Monod (1957) have stated that the permeases are highly stereospecific and gave evidence for eight separate and distinct permeases for Escherichia coli. Shilo \& Stanier (1957) found that tartrate-oxidizing pseudomonads had separate induced transport systems for each of the three tartrate isomers. If we assume that our experiments with $P$ seudomonas aeruginosa provide reasonable evidence for the existence of permeases for the acids of the tricarboxylic cycle, then an examination of the patterns of oxidative activity, i.e. the presence or absence of lag periods for organisms grown on different substrates, should give some indication of the possible number of specific permeases. From the results given in Table 1 it can be seen that growth on different substrates produced organisms with distinct adaptive patterns for the oxidation of citrate, acetate, fumarate and succinate, suggesting that 


\section{Permeases in Pseudomonas aeruginosa}

there are separate permeases for each of these acids. With this organism malate, pyruvate and $\alpha$-oxoglutarate always gave the same pattern whatever the growth medium, so that it is not possible to say whether or not they are carried into the cell by different permeases. An examination of the results which Barrett \& Kallio (1953) found with $P$. fluorescens shows separate and distinct patterns for citrate, acetate, $\alpha$-oxoglutarate, fumarate and succinate, but the patterns for malate and pyruvate oxidation were identical. The results given by Kogut \& Podoski (1953) show separate and distinct patterns for citrate, acetate, malate, pyruvate and $\alpha$-oxoglutarate, but do not distinguish between succinate and fumarate. If it be permissible to combine these results with three different pseudomonads, then all the substances we have discussed have distinct permeases. However, further work will be needed to establish conclusively the specificity of the permeases concerned with the transport of these organic acids.

The implicit assumption has been made that permease formation can be adaptive and is then induced by the presence of the relevant compound. Rickenberg et al. (1956) showed that $\beta$-galactoside-permease is induced by compounds which are also inducers of the enzyme $\beta$-galactosidase, but that the capacity of different compounds to induce the permease is not always the same as their capacity to induce the enzyme $\beta$-galactosidase. In the experiments which we have described with Pseudomonas aeruginosa we have interpreted the results as showing that the substrates of the oxidative enzymes induce the formation of their own permeases, and that whereas the enzymes concerned in the tricarboxylic acid cycles are constitutive, the permeases are adaptive. It has been suggested that if the substrate of an adaptive enzyme were an essential cell-metabolite then, since it would always be present in the cell, it would induce its enzyme which would then appear as a constitutive enzyme. In the same way one might expect that a compound which was a normal cell-metabolite would be able to induce the formation of its permease. In the case of the substrates which we have investigated, which are all normal cell-metabolites, it may be that the concentration of the free compound in the cell when it has not been added to the medium, is too low to induce the permease. It might also be possible that permease production is suppressed, so that compounds which are essential metabolites are retained in the cell. There is evidence in certain organisms that permease production may be inhibited by other compounds present in the growth medium. Rickenberg et al. (1956) showed that the induction of $\beta$-galactoside-permease, as well as galactosidase, was inhibited by glucose. H. Green, reported by Davis (1956), found that Aerobacter aerogenes grown on glucose, but not on succinate, was impermeable to citrate. When organisms were grown on citrate with glucose, citrate utilization was inhibited, although extracts of the organisms still oxidized citrate. In these experiments glucose appeared to inhibit the formation of citratepermease.

The site of the bacterial permeases has not yet been finally established, although all the available evidence would support the hypothesis that they are situated in the protoplast membrane of Gram-positive bacteria and in 
whatever is the equivalent osmotic barrier in Gram-negative bacteria. Rickenberg (1957) showed that the osmotically-fragile bodies formed by lysozyme treatment of Escherichia coli retained the ability of whole organisms for accumulating $\beta$-galactosides. The permeases must therefore be associated with those layers of the bacterial cell wall which are unchanged by lysozyme treatment. If the action of chloramphenicol towards Gram-positive and Gramnegative bacteria is similar, then our work showing that chloramphenicol inhibits permease synthesis would suggest that the permeases are not situated in the rigid layers of the wall. Mandelstam \& Rogers (1958) and Hancock \& Park (1958) showed that in Staphylococcus aureus chloramphenicol inhibited protein synthesis but not the synthesis of cell walls. Moreover, Crathorn \& Hunter (1958) found that although chloramphenicol did not inhibit the synthesis of the cell-wall peptide, which appears to be elaborated in the protoplast membrane of Bacillus megaterium, it inhibited the incorporation of amino acids into the protein (Gilby, Few \& McQuillen, 1958) present in the membrane itself. Evidence of the site of citrate-permease in Aerobacter aerogenes has been provided by some experiments by Green, reported by Davis (1956). He showed that the barrier to citrate-permeability in glucosegrown organisms was situated in the outer layers of the organism rather than at sites within it.

The pseudomonads are an omnivorous group of organisms which are capable of using a very large number of organic compounds of carbon and nitrogen. If each of these substances required a separate permease and enzyme, the problem of accommodating all these protein molecules becomes considerable, particularly as many of the enzymes, as well as the permeases, are probably associated with the osmotic barrier of the cell or at least with the 'small particle' fraction (Alexander, 1956). It seems likely that the adaptive formation of many of the enzymes and permeases has provided the organisms with a means of overcoming this difficulty.

We are grateful to Miss G. Gurnett for excellent technical assistance and to the University of London Central Research Fund for grants for apparatus.

One of us (P.M.M.) is a Beit Memorial Fellow.

\section{REFERENCES}

Alexander, M. (1956). Localization of enzymes in the microbial cell. Bact. Rev. 20, 67.

Barrett, J. T. \& Kallio, R. E. (1953). Terminal respiration in Pseudomonas fluorescens. Component enzymes of the tricarboxylic acid cycle. J. Bact. 66, 517 .

Cohen, G. N. \& Monod, J. (1957). Bacterial permeases. Bact. Rev. 21, 169.

Cohen, G. N. \& Rickenberg, H. V. (1955). Étude directe de la fixation d'un inducteur de la $\beta$-galactosidase par les cellules d'Escherichia coli. C.R. Acad. Sci., Paris, 240, 466.

Crathorn, A. R. \& Hunter, G. D. (1958). Amino acid 'exchange' and protein synthesis in cell walls of Bacillus megaterium. Biochem. J. 69, 47 P.

Creaser, E. H. (1956). The assimilation of amino acids by bacteria. 22. The effect of 8-azaguanine upon enzyme formation in Staphylococcus aureus. Biochem. J. 64, 539 . 
Davis, B. D. (1956). Relations between enzymes and permeability (membrane transport) in bacteria. In Enzymes: Units of Biological structure and Function. Henry Ford Hosp. Symp. 4, 509.

Gilby, A. R., Few, A. V. \& McQuillen, K. (1958). The chemical composition of the protoplast membrane of Micrococcus lysodeikticus. Biochim. biophys. Acta, $29,21$.

Gray, C. T. (1952). The malonic decarboxylase of Pseudomonas aeruginosa. J. Bact. $63,813$.

Hancock, R. \& Park, J. T. (1958). Cell-wall synthesis by Staphylococcus aureus in the presence of chloramphenicol. Nature, Lond. 181, 1050.

HAYAISHI, O. (1954). Mechanism of the enzymatic decarboxylation of malonic acid. Fed. Proc. 13, 226.

Kogut, M. \& Podoski, E. P. (1953). Oxidative pathways in a fluorescent Pseudomonas. Biochem. J. 55, 800.

MANDElstam, J. \& Rogers, H. J. (1958). Chloramphenicol-resistant incorporation of amino-acids into staphylococci and cell-wall synthesis. Nature, Lond. 181, 956.

Meadow, P. \& Clarke, P. H. (1958). The oxidation of tricarboxylic acid cycle intermediates by Pseudomonas aeruginosa. Biochem. $J .69,18 \mathrm{P}$.

Milner, H. W., Lawrence, N. S. \& French, C. S. (1950). Colloidal dispersion of chloroplast material. Science, 111, 633.

Rickenberg, H. V. (1957). The site of galactoside-permease activity in Escherichia coli. Biochim. biophys. Acta, 25, 206.

Rickenberg, H. V., Cohen, G. N., Buttin, G. \& Monod, J. (1956). La galactosidepermease d'Escherichia coli. Ann. Inst. Pasteur, 91, 829.

Shilo, M. \& Stanier, R. Y. (1957). The utilization of tartaric acids by Pseudomonads. J. gen. Microbiol. 16, 482.

Stone, R. W. \& Wilson, P. W. (1952). Respiratory activity of cell-free extracts from azotobacter. J. Bact. 63, 605.

Wolfe, J. B., IVler, D. \& RitTENBERG, S. C. (1954). Malonate decarboxylation by Pseudomonas fluorescens. 1. Observations with dry cells and cell-free preparations. J. biol. Chem. 209, 867.

Wolfe, J. B., Ivler, D. \& RitTenberg, S. C. (1955). Malonate oxidation by dry cells and cell-free extracts of Pseudomonas aeruginosa. J. Bact. 69, 240.

(Received 25 August 1958) 